\title{
Tranexamic acid for antenatal bleeding of unknown origin in the second and third trimesters: A prospective clinical trial
}

\section{Abstract}

Background and objective: Vaginal bleeding is a common complication in pregnancy and is associated with poor perinatal outcomes. This study aimed to determine the efficacy of tranexamic acid in stopping vaginal bleeding during pregnancy and improving perinatal outcomes.

Methods: A prospective clinical trial was conducted on 137 pregnant women with vaginal bleeding of unknown causes in the second and third trimesters of pregnancy who were admitted to Maternity Teaching Hospital, Erbil city, Kurdistan region, Iraq from February 2016 to November 2019. Tranexamic acid was administered to one group and normal supportive care to another group in a sequential manner. The Mann-Whitney test was used to compare the mean rank of the times of admission. Factors that were significantly associated with stoppage of bleeding were entered into a binary logistic regression model.

Results: Bleeding was stopped in $90 \%$ of women who received tranexamic acid. There was a significant difference in low Apgar score, the rate of low birth weight, and the rate of unfavorable perinatal outcome in the supportive care group than that in the tranexamic acid group. Predictors for not stopping bleeding were supportive care management compared with tranexamic acid (odds ratio $(\mathrm{OR})=13.38$; 95\% confidence interval $(\mathrm{Cl})=3.60-49.67$ ), and $21-32$ weeks gestation compared with $\geq 37$ weeks $(\mathrm{OR}=6.52 ; 95 \% \mathrm{Cl}=1.66-25.63)$. Conclusion: Tranexamic acid in second and third trimesters bleeding is effective for rapidly arresting bleeding with a favorable neonatal outcome.

Keywords: Antifibrinolytic agent; Miscarriage; Neonatal death; Preterm labor; Tranexamic acid.

\section{Introduction}

Vaginal bleeding is a common complication in pregnancy, affecting up to one quarter of pregnancies. $^{1}$ Unexplained antenatal bleeding of unknown origin in the second and third trimesters was reported in $2 \%$ of pregnancies presented with vaginal bleeding. $^{2}$ Vaginal bleeding during the second and third trimesters is associated with a poor pregnancy outcome and increased risk of low birth weight, preterm birth, and increased perinatal mortality and morbidity rates. ${ }^{3-5}$ Some studies have suggested that the adverse effects of vaginal bleeding in pregnancy are related to the heaviness of the bleeding, repeated events, and late onset of pregnancy. ${ }^{6}$ Tranexamic acid is a synthetic lysine analogue, and an antifibrinolytic that is used for prophylaxis and treatment of bleeding caused by a local or generalized hyperfibrinolysis and other hemorrhagic conditions. It also stabilizes preformed clots during the physiological process of hemostasis and prolongs their dissolution. ${ }^{7}$ Studies examining antifibrinolytic as a method for treating heavy menstrual bleedings demonstrated that tranexamic acid could reduce nonsurgical, low-volume, uterine bleeding. ${ }^{8}$ Intravenous tranexamic acid is also have used to decrease blood loss during

${ }^{1}$ Department of Obstetrics and Gynecology, Kurdistan Board of Medical Specialties, Erbil, I raq.

* Correspondence: ariana_jawad@yahoo.com 
cesarean section, and it has a therapeutic role during heavy blood loss in cesarean section. ${ }^{9-11}$ Furthermore Tranexamic acid is also used to prevent and manage postpartum hemorrhage after vaginal bleeding, regardless of whether the bleeding is due to genital tract trauma or other causes. ${ }^{12}$ An international, randomized clinical trial, the WOMAN trial, published in 2017, showed that tranexamic acid reduced death due to bleeding in women with postpartum hemorrhage. ${ }^{13}$ Additionally, there were no adverse effects when tranexamic acid was used to treat postpartum hemorrhage. This large trial showed that tranexamic acid had no thromboembolic side effects. Therefore, tranexamic acid use is assumed to be safe in pregnancy. However, there are few published studies on the use of tranexamic acid in pregnancy and these articles were of low methodological quality as was reviewed in an article conducted by Peitsidis and Kadir. ${ }^{14}$ There is a lack of knowledge regarding antenatal bleeding of unknown origin and its importance. Currently, there is a clinical need for effective interventions for antenatal bleeding of unknown origin in pregnancy, but the use of tranexamic acid for managing bleeding in pregnancy is scarce. Therefore, this study aimed to compare the cessation vaginal bleeding and perinatal outcomes between patients who received tranexamic acid and those who received normal supportive care.

\section{Methods}

\section{Study design and setting}

A prospective clinical trial with a sequential group allocation method (the first woman received tranexamic acid and the second woman received supportive care, and this was repeated consecutively) was conducted in 137 women. These women were admitted to the Maternity Teaching Hospital, Erbil city, Kurdistan Region, Iraq, from February 2016 to November 2019 with the complaint of $A B O U$. Women were included in the study after obtaining informed written consent from each participant. Participants were assured that confidentiality would be maintained and that their information would only be used for research purposes. The trial protocol was approved by the Research Ethics Committee of Hawler Medical University (Ref. 7/02 dated 26-6-18) and the Institutional Review Committee of the Maternity Teaching Hospital. The trial is registered at Clinical Trials.gov (Identifier: NCT03632824).

Study population

\section{Inclusion and exclusion criteria for both groups}

The following inclusion criteria were used: pregnant women with unknown origin of vaginal bleeding in the second and third trimesters who had vaginal bleeding that soaked the underwear or required a pad; a gestational age of 13-34 weeks; those who were pregnant for the first time or had previous parity; those who were stable hemodynamically; and those who accepted to participate in the trial. The following exclusion criteria were used: pregnant women who had spotty vaginal bleeding one time; women who had hypersensitivity to tranexamic acid and those with acquired defective color vision; women with a history of venous thromboembolism; having pre-existing medical conditions that could affect pregnancy outcomes (diabetes mellitus, hypertension, renal disease); smokers; and those who refused to participate in the trial.

\section{Allocations to both groups}

Women were allocated in a sequential matter. Every other woman was assigned to the tranexamic acid group or supportive care group. This allocation was performed by the obstetrician who interviewed the patients and who was informed to continue allocation in a stepwise manner.

Definitions of clinical conditions and outcomes

Antenatal bleeding of unknown origin in the second and third trimesters of pregnancy was defined as vaginal bleeding from 13 weeks up to just before labor and without 
abruption, placenta accreta, vasa previa, and local causes in the vagina or cervix for vaginal bleeding (e.g., cervical erosions, polyps, or cancer). Abdominal ultrasound was performed to determine placental position within the uterine cavity and any evidence of placental abruption. Abdominal Doppler ultrasound was conducted to exclude vasa previa by searching for fetal vessels at the internal os of the cervix. After excluding placenta previa, a vaginal examination was carefully performed using a Cusco's speculum examination to exclude any local causes from the vagina and cervix for antenatal bleeding of unknown origin. The duration and heaviness for each bleeding episode were recorded. The number of episodes was classified as single or multiple. The amount of bleeding was categorized as light spotting, which was defined as when women detected bleeding by wiping but did not require the use of sanitary pad protection. Women with light spotting were excluded from the study. Heavy bleeding was defined when bleeding soaked the underwear, or it required a pad. ${ }^{15}$ Neonatal outcomes that were evaluated included viability, birth weight, Apgar scores at 1 and 5 minutes of life, neonatal intensive care unit admission, and death of the newborn within one week of life. Low birth weight was defined as a weight $<2.5 \mathrm{~kg}$ at birth. ${ }^{16}$ Stillbirth was defined as the death of the fetus before complete expulsion or extraction from its mother and showing no signs of life, such as the beating of the heart, pulsation of the umbilical cord, or definite movement of voluntary muscles, with a birth weight > $1000 \mathrm{~g} \cdot{ }^{17}$ Early neonatal death was defined as death that occurred within six days following birth. ${ }^{18}$ Perinatal mortality was defined as stillbirth plus early neonatal death. ${ }^{18}$ Preterm birth was defined as delivery of the fetus after 20 weeks gestation and before 36 $6 / 7$ weeks of pregnancy. ${ }^{19}$ Apgar scores between 7 and 10 points at 5 minutes were considered "reassuring," those between 4 and 6 as "moderately abnormal", and lower scores as "low" according to the American Academy of Paediatrics $2017 .{ }^{20}$ Newborns with Apgar scores of 4-6 and $<4$ were admitted to the neonatal intensive care unit. The response-outcome measure in both groups regarding cessation of vaginal bleeding was subjectively evaluated as follows: (1) vaginal bleeding stopped with one or repeated courses of tranexamic acid in tranexamic acid group and with many times admission to hospital in supportive care group; (2) bleeding did not stop, and the pregnancy ended in miscarriage or preterm delivery in both groups. ${ }^{14}$ Eligible participants were admitted to the hospital after signing informed written consent. Data on the clinical and obstetric history were gathered using questionnaires. These data included demographic characteristics, pre-existing medical conditions that could affect pregnancy outcomes, gestational age as confirmed using the last menstrual cycle and first trimester ultrasound scanning, body mass index $\left(\mathrm{kg} / \mathrm{m}^{2}\right)$, and a history of the amount of vaginal bleeding, number of pads per day, recurrent attack or first time of having bleeding, and whether bleeding was associated with pain. Antepartum complications that were assessed included preterm birth. Intrapartum evaluations included the requirement for induction of labor, mode of delivery, the requirement for elective or emergency cesarean section for obstetric and fetal indications, and gestational age at the time of delivery. The perinatal outcome was assessed in both groups, including newborns who were stillborn and those with early neonatal death. Data were collected by one responsible person, who had full access to all of the data in the study and took responsibility for the integrity of the data.

\section{Clinical protocols and follow-up for the} tranexamic acid group

Pregnant women in the tranexamic acid group were admitted to the hospital for 48 hours, where tranexamic acid was administered intravenously. Women in the tranexamic acid group were discharged 
https:/ / doi.org/ 10.15218/ zjms.2021.017

from the hospital when oral therapy started on the third day. They were then followed up each week regarding self-estimation of the amount of vaginal blood loss. Ultrasound was performed fortnightly in cases of cessation of vaginal bleeding. Ultrasound was performed every 48 hours in those who responded gradually or required recurrent use of tranexamic acid to confirm fetal well-being and confirm the placenta's location and the presence of any subchorionic or retroplacental hematoma. Women diagnosed to have abruption placenta were excluded from the analysis of data. Women who did not respond to treatment in both groups and were accompanied by uterine contractions and cervical dilatation that ended in miscarriage or preterm labor remained in the hospital, and full care of the delivered woman and newborn were achieved. Fetal wellbeing was followed up by a fetal kick count by the mother and abdominal ultrasound using a biophysical profile. Doppler ultrasound for the umbilical artery was used in women with decreased fetal movement. In this case, the woman delivered via emergency cesarean section, and Doppler ultrasound was also used to exclude vas previa in the cervical internal os.

\section{Tranexamic acid group}

This study group included an interventional arm of 70 women who received tranexamic acid. Women in the tranexamic acid group received $1 \mathrm{~g}$ (2 ampules each of $500 \mathrm{mg}$ ) of tranexamic acid (Trenaxa; Macleods Pharmaceuticals Pvt. Ltd., Mumbai, India) intravenously twice daily in the acute stage of bleeding for 48 hours. This was followed by 500 $\mathrm{mg}$ tranexamic acid tablets (Trenaxa; Macleods Pharmaceuticals Pvt. Ltd.) three times daily for five days. The patients were then followed up for recurrence of bleeding during pregnancy. The course of treatment was repeated again if bleeding recurred. The hospital data safety and monitoring board ensured the continued safety of the patients.
Clinical protocols and follow-up for the supportive care group

Women in this group $(n=67)$ received the usual expectant management care. They were generally hospitalized for management and underwent regular coagulation blood (prothrombin time, activated partial thromboplastin time, fibrinogen concentration, platelet counts, hemogram, coagulation factor VIII and von Willebrand factor activity) in the first admission time and ultrasound examination at least once a week. For women who were hospitalized at 22 weeks of gestation or later, regular coagulation was also carried out for them at the first admission event, fetal heart rate monitoring using cardiotocography was performed at least once daily, and ultrasound was performed weekly to confirm fetal wellbeing and placental location and any retroplacental bleeding. When uterine contractions were associated with unpleasant subjective symptoms, this condition was managed by bed rest, intravenous tocolytic therapy was administered, and dexamethasone injection were provided for all women who were between 24 weeks \pm 0 days and 33 weeks \pm 6 days of gestation in whom delivery was expected. The patients were followed up for recurrence of bleeding during pregnancy. The course of follow-up in the hospital was repeated again if bleeding recurred. Patients were followed up until delivery, and the mode of delivery and maternal and newborn outcomes were recorded.

\section{Power of sample size estimation}

Epi-info software from the Centres for Disease Control and Prevention (https://www.cdc.gov/epiinfo/support/ downloads.html) was used to calculate the sample size. The sample size was calculated assuming that the success rate in the intervention group was $90 \%$ compared with $60 \%$ for the control group, with an odds ratio (OR) of 6. This calculation was determined according to a pilot study on 20 pregnant women 
because we could not find a relevant published article to determine the response to tranexamic acid in pregnant women with bleeding. A sample size of 49 pregnant women for each group was sufficient to achieve a 95\% confidence interval $(\mathrm{Cl})$ and a power of $90 \%$. The sample size was increased to 70 for each group to account for non-response and loss to follow-up.

\section{Missing data}

Prevention of missing data was attempted by carefully collecting the data. Before the start of enrolling participants, training was conducted for all personnel who were related to the study, such as enrolment of the participants and implementation of treatment or intervention. The collection of data was achieved by a researcher and a well-trained staff member in the hospital.

\section{Statistical analysis}

Data were analyzed using the statistical package for the social sciences (SPSS, version 22, IBM, USA). The Chi-square test of association was used to compare proportions. The Student's $t$ test of two independent samples was used to compare two means. The Mann-Whitney test was used to compare the mean rank of the times of admission to the hospital of the two study groups. Factors that were significantly associated (by the Chi-square test) with stoppage of bleeding were entered into a binary logistic regression model. A $P$ value of $\leq 0.05$ was considered statistically significant

\section{Results}

A total of 152 women were assessed for illegibility, and nine women were excluded for not meeting the inclusion criteria. A total of 143 women were allocated in a sequential manner into two groups of 73 women in the tranexamic acid group and 70 women in the supportive care group. After excluding missing cases for follow up, and those who were not allocated to both groups, data from 137 women were analyzed (70 in the tranexamic acid group and 68 in the supportive care group) (Figure 1).

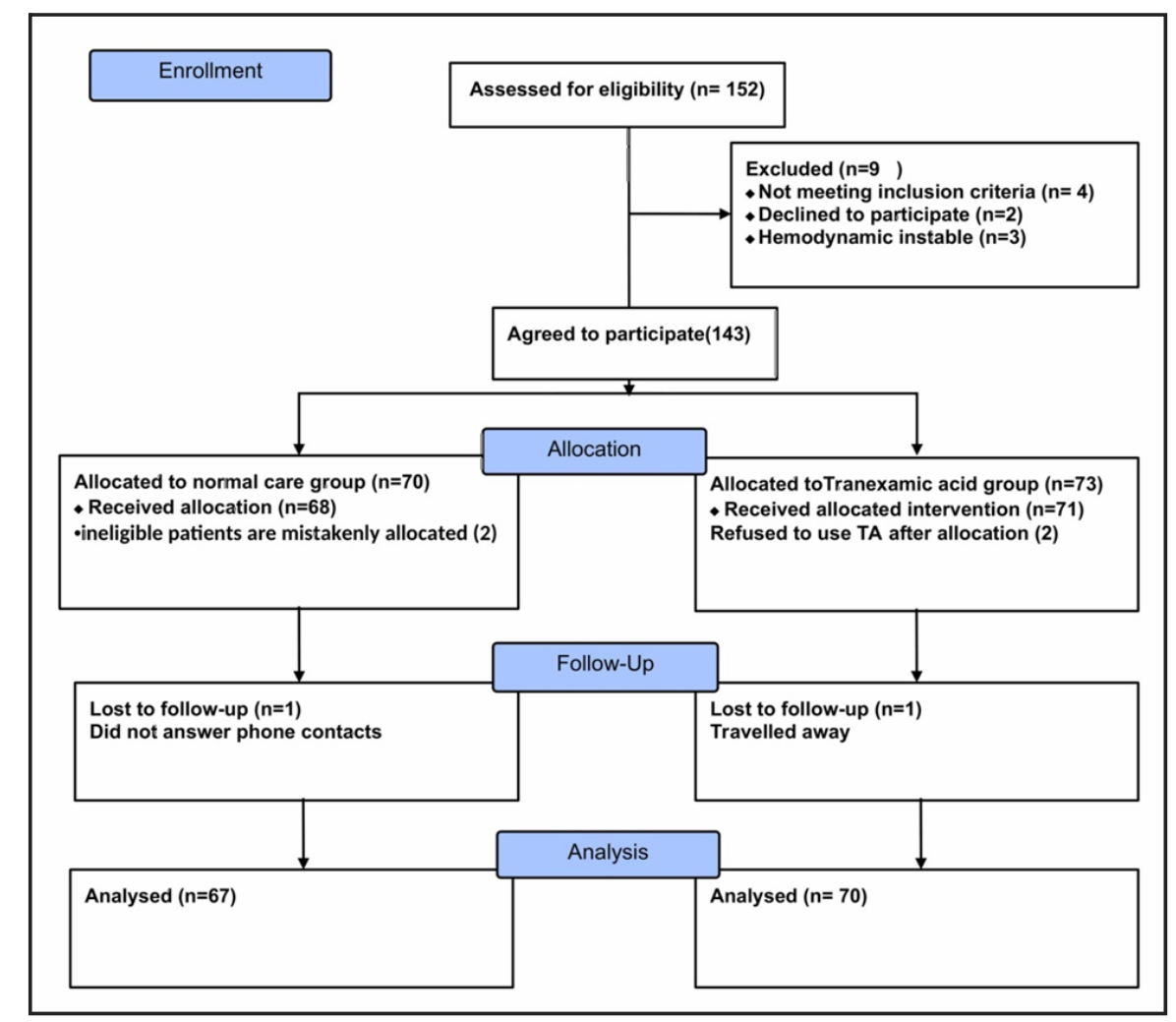

Figure 1: Flowchart of the research. 
No significant difference was detected regarding the distribution of age, parity, gestational age on admission, and body mass index between the two groups (Table 1). Around $53 \%$ of women in the tranexamic acid group delivered vaginally, and $30.6 \%$ of women in the supportive care group delivered vaginally. A significantly higher percentage (40.3\%) of women in the supportive care group delivered by cesarean section compared with women in the tranexamic acid group $(19.7 \%, P=0.002)$.

Table 1: Basic characteristics of the study groups.

\begin{tabular}{|c|c|c|c|c|c|c|c|}
\hline & \multicolumn{2}{|c|}{$\begin{array}{l}\text { Tranexamic } \\
\text { acid group }\end{array}$} & \multicolumn{2}{|c|}{$\begin{array}{c}\text { Supportive care } \\
\text { group }\end{array}$} & \multicolumn{2}{|c|}{ Total } & \multirow[t]{2}{*}{$P$ value } \\
\hline & $\mathbf{n}$ & (\%) & $\mathbf{n}$ & (\%) & $\mathbf{n}$ & (\%) & \\
\hline \multicolumn{8}{|l|}{ Age (years) } \\
\hline$<25$ & 16 & $(22.9)$ & 15 & $(22.4)$ & 31 & $(22.6)$ & $0.946^{*}$ \\
\hline $25-29$ & 17 & $(24.3)$ & 16 & $(23.9)$ & 33 & $(24.1)$ & \\
\hline $30-34$ & 19 & $(27.1)$ & 21 & (31.3) & 40 & $(29.2)$ & \\
\hline$\geq 35$ & 18 & $(25.7)$ & 15 & $(22.4)$ & 33 & $(24.1)$ & \\
\hline Total & 70 & $(100.0)$ & 67 & $(100.0)$ & 137 & $(100.0)$ & \\
\hline Mean $( \pm \mathrm{SD})$ & 29.46 & $(6.50)$ & 29.69 & $(6.35)$ & & & $0.835 \dagger$ \\
\hline \multicolumn{8}{|l|}{ Parity } \\
\hline Nulliparous & 21 & $(30.0)$ & 19 & $(28.4)$ & 40 & $(29.2)$ & $0.851^{*}$ \\
\hline Multiparous & 49 & $(70.0)$ & 47 & $(70.1)$ & 96 & $(70.1)$ & \\
\hline Grand multiparous & 0 & $(0.0)$ & 1 & $(1.5)$ & 1 & $(0.7)$ & \\
\hline Total & 70 & $(100.0)$ & 67 & $(100.0)$ & 137 & $(100.0)$ & \\
\hline Mean $( \pm S D)$ & 1.37 & $(1.17)$ & 1.42 & $(1.18)$ & & & $0.817 \dagger$ \\
\hline \multicolumn{8}{|l|}{ Gestational age on admission } \\
\hline 13-20 & 39 & $(55.7$ & 35 & $(52.2)$ & 74 & $(54.0)$ & $0.683^{*}$ \\
\hline$>20$ weeks & 31 & $(44.3$ & 32 & $(47.8)$ & 63 & $(46.0)$ & \\
\hline Total & 70 & $(100.0$ & 67 & $(100.0)$ & 137 & $(100.0)$ & \\
\hline Mean $( \pm S D)$ & 21.24 & $(6.23)$ & 21.64 & $(5.87)$ & & & $0.701 \dagger$ \\
\hline \multicolumn{8}{|l|}{ BMI $\left(\mathrm{kg} / \mathrm{m}^{2}\right)$} \\
\hline$<25$ & 10 & $(14.3)$ & 10 & $(14.9)$ & 20 & $(14.6)$ & $0.964^{*}$ \\
\hline $25-29$ & 34 & $(48.6)$ & 31 & $(46.3)$ & 65 & $(47.4)$ & \\
\hline$\geq 30$ & 26 & $(37.1)$ & 26 & $(38.8)$ & 52 & $(38.0)$ & \\
\hline Total & 70 & $(100.0)$ & 67 & $(100.0)$ & 137 & $(100.0)$ & \\
\hline Mean $\pm(S D)$ & 29.10 & $(4.15)$ & 29.18 & $(4.10)$ & & & $0.902 \dagger$ \\
\hline \multicolumn{8}{|l|}{ Mode of delivery } \\
\hline Spontaneous vaginal delivery & 35 & $(53.0)$ & 19 & $(30.6)$ & 54 & $(42.2)$ & $0.002^{*}$ \\
\hline Elective CS & 16 & $(24.2)$ & 9 & $(14.5)$ & 25 & $(19.5)$ & \\
\hline Emergency CS & 13 & (19.7) & 25 & $(40.3)$ & 38 & $(29.7)$ & \\
\hline Induction of labor & 2 & $(3.0)$ & 9 & $(14.5)$ & 11 & $(8.6)$ & \\
\hline Total & 66 & $(100.0)$ & 62 & $(100.0)$ & 128 & $(100.0)$ & \\
\hline
\end{tabular}

${ }^{*}$ Analysed by the Chi-square test; †analysed by the $t$ test for two independent samples. BMI: body mass index; CS: cesarean section 
A significantly higher proportion of women in the tranexamic acid group delivered at $\geq 37$ weeks of gestation compared with women in the supportive care group $(P<0.001$, Table 2$)$. There was a significant difference in the distribution of the Apgar score 5 minutes after delivery. A total of $89.4 \%$ of women in the tranexamic acid group had an Apgar score of $\geq 7$ compared with $66.1 \%$ of women in the supportive care group $(P=0.003)$. The rate of low birth weight in the supportive care group was significantly higher than that in the tranexamic acid group (0.03). The rate of perinatal outcome in the supportive care group was significantly better $(52.2 \%)$ than that in the tranexamic acid group $(25.7 \%, P=0.01)$. (Table 2)

Table 2: Newborn outcomes in both groups.

\begin{tabular}{|c|c|c|c|c|c|c|c|}
\hline & \multicolumn{2}{|c|}{$\begin{array}{c}\text { Tranexamic acid } \\
\text { group }\end{array}$} & \multicolumn{2}{|c|}{$\begin{array}{c}\text { Supportive care } \\
\text { group }\end{array}$} & \multicolumn{2}{|c|}{ Total } & \multirow{2}{*}{$P$ value } \\
\hline & n & $(\%)$ & n & $(\%)$ & $\mathbf{n}$ & (\%) & \\
\hline \multicolumn{8}{|c|}{ Gestational age at delivery (weeks) (newborn age) } \\
\hline $21-32$ & 2 & $(3.0)$ & 18 & $(29.0)$ & 20 & $(15.6)$ & \multirow{3}{*}{$<0.001^{*}$} \\
\hline $33-36$ & 20 & $(30.3)$ & 27 & $(43.5)$ & 47 & $(36.7)$ & \\
\hline$\geq 37$ & 44 & $(66.7)$ & 17 & $(27.4)$ & 61 & $(47.7)$ & \\
\hline Total & 66 & $(100.0)$ & 62 & $(100.0)$ & 128 & $(100.0)$ & \\
\hline Mean $( \pm \mathrm{SD})$ & 36.58 & $(2.11)$ & 34.15 & $(3.35)$ & & & $<0.001 \dagger$ \\
\hline \multicolumn{8}{|c|}{ Apgar score at 5 minutes } \\
\hline Low & 2 & (3.0) & 3 & $(4.8)$ & 5 & (3.9) & \multirow{3}{*}{$0.003^{*}$} \\
\hline Moderate & 5 & $(7.6)$ & 18 & $(29.0)$ & 23 & $(18.0)$ & \\
\hline Normal & 59 & $(89.4)$ & 41 & $(66.1)$ & 100 & $(78.1)$ & \\
\hline Total & 66 & $(100.0)$ & 62 & $(100.0)$ & 128 & $(100.0)$ & \\
\hline Mean $( \pm \mathrm{SD})$ & 8.59 & $(2.02)$ & 7.71 & $(2.58)$ & & & $0.034 \dagger$ \\
\hline \multicolumn{8}{|c|}{ Birth weight (kg) } \\
\hline$<2.5$ & 3 & $(4.5)$ & 10 & $(16.1)$ & 13 & $(10.2)$ & \multirow[b]{2}{*}{$0.030^{*}$} \\
\hline$\geq 2.5$ & 63 & $(95.5)$ & 52 & $(83.9)$ & 115 & $(89.8)$ & \\
\hline Total & 66 & $(100.0)$ & 62 & $(100.0)$ & 128 & $(100.0)$ & \\
\hline Mean $( \pm S D)$ & 3.10 & $(0.42)$ & 2.79 & $(0.55)$ & & & $<0.001$ \\
\hline \multicolumn{8}{|c|}{ Perinatal outcome } \\
\hline FSB & 0 & $(0 \%)$ & 2 & $(3 \%)$ & 2 & $(2 \%)$ & \multirow[b]{2}{*}{$0.01^{*}$} \\
\hline END & 1 & $(1 \%)$ & 5 & $(6 \%)$ & 6 & $(6 \%)$ & \\
\hline
\end{tabular}

*Analyzed by the Chi-square test; †analyzed by the $t$ test for two independent samples. FSB: fresh stillbirth; END: early neonatal death 
The bleeding stopped in the majority (90\%) of women in the tranexamic acid group compared with only $46.3 \%$ of women in the supportive care group $(P<0.001)$. A total of $91.4 \%$ of women in the tranexamic acid group required one to two times of admission to the hospital, while $70 \%$ of those in the supportive care group required $\geq$ five times of admission $(P<0.001$, Table 3$)$. Table 4 shows that the bleeding status is only significantly associated with gestational age at delivery (age of the newborn), in addition to the 'group' whether tranexamic acid or normal care (also significantly associated with the bleeding status).

Table 3: Bleeding status and admission times in the two study groups.

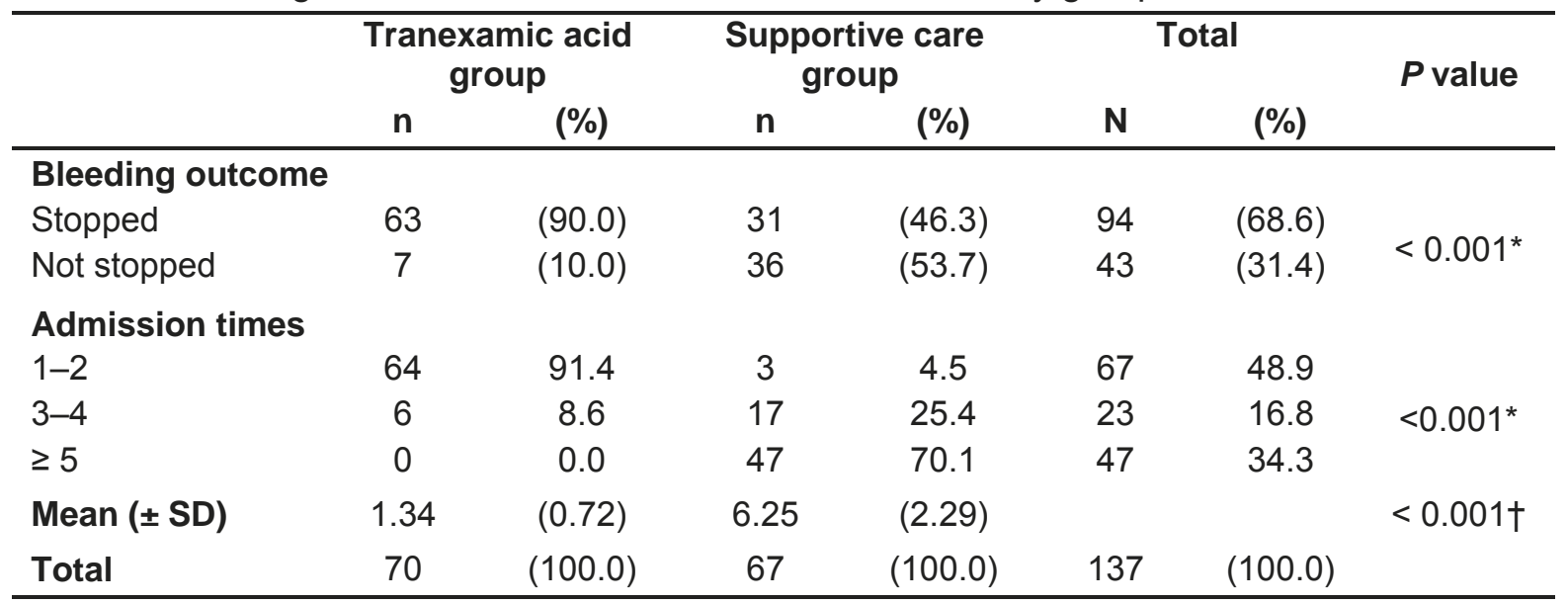

*Analyzed by the Chi-square test; †analyzed by the Mann-Whitney test

Table 4: Bleeding status by the studied factors.

\begin{tabular}{|c|c|c|c|c|c|c|c|}
\hline \multicolumn{8}{|c|}{ Bleeding status } \\
\hline & \multicolumn{2}{|c|}{ Stopped } & \multicolumn{2}{|c|}{ Not stopped } & \multicolumn{2}{|c|}{ Total } & \multirow{2}{*}{$P$ value } \\
\hline & No. & (\%) & No. & (\%) & No. & $(\%)$ & \\
\hline \multicolumn{8}{|l|}{ Age (years) } \\
\hline$<25$ & 24 & $(77.4)$ & 7 & $(22.6)$ & 31 & $(100.0)$ & \multirow{4}{*}{$0.297 \dagger$} \\
\hline $25-29$ & 23 & (69.7) & 10 & (30.3) & 33 & $(100.0)$ & \\
\hline $30-34$ & 23 & (57.5) & 17 & $(42.5)$ & 40 & $(100.0)$ & \\
\hline$\geq 35$ & 24 & $(72.7)$ & 9 & (27.3) & 33 & $(100.0)$ & \\
\hline \multicolumn{8}{|l|}{ BMI } \\
\hline$<25$ & 17 & (85.0) & 3 & $(15.0)$ & 20 & $(100.0)$ & \multirow{3}{*}{$0.125 \dagger$} \\
\hline $25-29$ & 40 & (61.5) & 25 & $(38.5)$ & 65 & $(100.0)$ & \\
\hline$\geq 30$ & 37 & (71.2) & 15 & $(28.8)$ & 52 & $(100.0)$ & \\
\hline \multicolumn{8}{|l|}{ Parity } \\
\hline Nulliparous & 30 & $(75.0)$ & 10 & $(25.0)$ & 40 & $(100.0)$ & \multirow{3}{*}{$0.532^{*}$} \\
\hline Multiparous & 63 & (65.6) & 33 & (34.4) & 96 & (100.0) & \\
\hline Grand multiparous & 1 & $(100.0)$ & 0 & $(0.0)$ & 1 & $(100.0)$ & \\
\hline \multicolumn{8}{|c|}{ Gestational age at delivery } \\
\hline $21-32$ & 6 & $(30.0)$ & 14 & $(70.0)$ & 20 & $(100.0)$ & \multirow{3}{*}{$<0.001 \dagger$} \\
\hline $33-36$ & 34 & (72.3) & 13 & $(27.7)$ & 47 & $(100.0)$ & \\
\hline$\geq 37$ & 54 & $(88.5)$ & 7 & $(11.5)$ & 61 & (100.0) & \\
\hline Total & 94 & (68.6) & 43 & (31.4) & 137 & $(100.0)$ & \\
\hline
\end{tabular}

*By Fisher's exact test. $†$ By the Chi square test. 
https:/ / doi.org/ 10.15218/ zjms.2021.017

The predictors for not stopping bleeding were supportive care management compared with tranexamic acid $(\mathrm{OR}=13.38 ; 95 \% \mathrm{Cl}=3.60-49.67)$ and a gestational age of 21-32 weeks compared with $\geq 37$ weeks $(\mathrm{OR}=6.52$; $95 \% \mathrm{Cl}=1.66-25.63)($ Table 5$)$

\section{Discussion}

The main finding of the current study was the good perinatal outcome after using tranexamic acid for managing pregnant women who presented with abnormal vaginal bleeding in the second and third trimesters of pregnancy of unknown causes. The success rate of tranexamic acid for stopping bleeding was $90 \%$. Only four $(5.1 \%)$ women had a miscarriage, and there was one early neonatal death among 70 women in the tranexamic acid group. Intravenous administration of a potent fibrinolytic inhibitor, such as tranexamic acid, has two main effects of stabilizing local hemostatic coagulation and inhibiting the fibrinolytic activity of the blood. ${ }^{21}$ Therefore, these two processes can stop bleeding during pregnancy for unknown causes. Vaginal bleeding occurring in the second or third trimesters of pregnancy can variably affect the perinatal outcome. ${ }^{22}$ It is logical to assume that the main goal for any obstetrician responsible for managing pregnant women with bleeding is to stop the bleeding. Studies conducted on the use of tranexamic acid in pregnancy previously have many limitations regarding sample size, the design of the study, and interpretation of data as was recorded in a study conducted by Peitsidis and Kadir ${ }^{14}$ In our study, only two women delivered before 33 weeks' gestation compared with 44 women who delivered at $\geq 37$ weeks' gestation in the tranexamic acid group. However, in the supportive care group, 18 women delivered before 33 weeks' gestation and 18 delivered at $\geq 37$ weeks' gestation. This significant difference between groups suggests that tranexamic acid was able to prolong pregnancy secondary to stopping vaginal bleeding, which affects the perinatal outcome. A powerful and proportionate association between antenatal bleeding of unknown origin and preterm delivery has been shown. ${ }^{2}$ Bhandari et al conducted a research at Aberdeen Maternity Hospital, Scotland on 7517 women with antenatal vaginal bleeding of unknown origin, showed that the proportion of preterm delivery was $14.1 \%$ in women with antepartum hemorrhage of unknown origin. Additionally, after adjusting for confounding factors, an increased risk of preterm delivery was still associated with antenatal bleeding of unknown origin. ${ }^{23}$ In our study, tranexamic acid was associated with a higher rate of newborns with birth weight $>2.5 \mathrm{~kg}$. Bhandari et $\mathrm{al}^{23}$ also found that

Table 5: Binary logistic regression analysis of predicting not stopping bleeding (dependent variable) according to the type of management and gestational age (covariates).

\begin{tabular}{lccccc}
\hline & & & & \multicolumn{2}{c}{$95 \%$ Cl for OR } \\
& B & $P$ value & OR & Lower & Upper \\
\hline Group (supportive care) & 2.594 & $<0.001$ & 13.389 & 3.608 & 49.678 \\
Tranexamic acid (reference) & & & & & \\
GA at delivery (weeks) & & 0.023 & & & \\
$21-32$ & 1.876 & 0.007 & 6.529 & 1.663 & 25.637 \\
$33-36$ & 0.501 & 0.385 & 1.651 & 0.533 & 5.112 \\
$\geq 37$ (reference) & & & & & \\
Constant & -3.335 & 0.000 & 0.036 & & \\
\hline
\end{tabular}

$\mathrm{Cl}$ : confidence interval; OR: odds ratio; GA: gestational age. 
https:/ / doi.org/ 10.15218/ zjms.2021.017

the proportion of newborns with low birth weight in women with antenatal bleeding of unknown origin was almost twice that for women without it. With regard to the mode of delivery, women in the tranexamic acid group were more likely to deliver vaginally than have a cesarean section. Women with unexplained vaginal bleeding were more likely to have cesarean section than vaginal delivery. Women in the supportive care group were more likely to have non-elective cesarean sections and fewer spontaneous vaginal deliveries. These findings are in accordance with a retrospective, observational study conducted in 1431 singleton pregnant women with antenatal bleeding of unknown origin at King Edward Memorial Hospital (KEMH), Subiaco, Western Australia. ${ }^{24}$ Notably, this previous study showed that the perinatal mortality rate in women with vaginal bleeding in the second half of pregnancy is significantly higher than that in women without bleeding. In our study, there were no significant differences in demographic and obstetric outcomes between the two groups. This finding suggests that the effect of tranexamic acid was related to its own effect and was not due to any cofounder, such as age, parity, and body mass index. In the current study, admission to the hospital because of recurrent attacks of vaginal bleeding was more frequent in the supportive care group than in the tranexamic acid group. Admission to the hospital may be necessary, but it can be upsetting to the mother and her family. Therefore, admission to hospital during pregnancy is likely to disrupt the lives of women and their families, exacerbate anxiety of pregnant women, and may be associated with extra costs to women (loss of time at work or requirement for arranging for the care of other children at home) and to health service providers. ${ }^{25}$ Admission to hospital often affects women's emotional wellbeing, especially if they require frequent re-hospitalization. The study has many limitations. First one limitation of the study is that it was a prospective clinical trial, and the two groups were sequentially allocated to the tranexamic acid and supportive care groups. A randomized, controlled trial with a sufficient number of subjects is required to validate our results. Another limitation of this study is that it was based on patients from a single hospital in one specific biogeographical region. Therefore, this limits the generalizability of our results. Further multicentre studies with a larger sample size are required to confirm our results. Another limitation of the study is that all outcomes were evaluated by a single, non-independent physician who was also in charge of recruiting women. The Unavailability of published articles that used tranexamic acid for the management of bleeding of unknown cause in pregnancy is another limitation of the study that deprived us of comparing the result with other researches. Despite these limitations, this study investigated medication that is used cautiously during pregnancy because of fear of its thrombotic side effects. However, as mentioned above, the WOMAN trial showed that tranexamic acid reduced death due to bleeding in women with postpartum hemorrhage with no adverse effects. ${ }^{13}$ The study was conducted on women with unknown causes for vaginal bleeding. This is regarded as strength of the study because there is little evidence of using any intervention in this condition. How to manage pregnancies complicated by antenatal bleeding of unknown origin is unknown because the reason for bleeding remains unclear. Another strength of our study is that pregnant women were followed up to determine the amount of decrease and stoppage of bleeding up to the delivery of the newborn and at one week of the life of the newborn.

\section{Conclusion}

Tranexamic acid has the advantages of being a well-known medication in all branches of medicine, of having a relatively low cost, being available in almost all 
settings, and having the ability to be used safely in the treatment regimen for patients with unexplained causes of vaginal bleeding in the second and third trimesters of pregnancy. Tranexamic acid appears to be effective in arresting hemorrhage and prolonging pregnancy with a good neonatal outcome. A randomized, controlled trial with a sufficient number of subjects and statistical power is required to validate our results.

\section{Competing interests}

The author declares no competing interests.

\section{References}

1. Sharami SH, Darkhaneh RF, Zahiri Z, Milani F, Asgharnia $M$, Shakiba $M$, et al. The relationship between vaginal bleeding in the first and second trimester of pregnancy and preterm labor. Iran J Reprod Med 2013; 11:385-9.

2. Magann FE, Cummings JE, Niederhauser A, Rodriguez-Thompson D, McCormack R, et al. Antepartum bleeding of unknown origin in the second half of pregnancy: a review. Obstet Gynecol Surv 2005; 60:741-5.

3. Sakornbut E, Leeman, L, Fontaine P. Late pregnancy bleeding. Am Fam Physician 2007; 75(8):1199-206.

4. Weiss JL, Malone FD, Vidaver J, Ball RH, Nyberg DA, Comstock $\mathrm{CH}$, et al. Threatened abortion: a risk factor for poor pregnancy outcome, a population-based screening study. Am J Obstet Gynecol 2004; 190:745-50.

5. Calleja-Agius, J, Custo R, Brincat MP, Calleja N. Placental abruption and placenta praevia. Eur Clin Obstet Gynaecol 2006; 2:121-7.

6. Yang J, Savitz, DA. The effect of vaginal bleeding during pregnancy on preterm and small for gestational age births: US National Maternal and Infant Health Survey, 1988. Paediat Perinatal Epidemiol 2001; 15:34-9.

7. Pabinger I, Fries D, Schöchl H, Streif W, Toller W. Tranexamic acid for treatment and prophylaxis of bleeding and hyperfibrinolysis. Wien Klin Wochenschr 2017; 129(9):303-16.

8. Matteson KA, Rahn DD, Wheeler TL, Casiano E, Siddiqui NY, Harvie HS, et al. Nonsurgical management of heavy menstrual bleeding: a systematic review. Obstet Gynecol 2013; 121(3):632-43.

9. Movafegh A, Eslamian L, Dorabadi A. Effect of intravenous tranexamic acid administration on blood loss during and after cesarean delivery. Int J Gynecol Obstet 2011; 115:224-6.

10. Andrea SL, Keith AM, Ken NM, Janet KG, Bryan $\mathrm{RH}$, Måns $\mathrm{E}$, et al. Tranexamic acid treatment for heavy menstrual bleeding: a randomized controlled trial. Obstet Gynecol 2010; 116(4):865.

11. Gai MY, Wu LF, Su QF, Tatsumoto K. Clinical observation of blood loss reduced by tranexamic acid during and after caesarian section: a multicentre, randomized trial. Eur $\mathrm{J}$ Obstet Gynecol Reprod Biol 2004; 112(2):154-7.

12. World Health Organization. Updated WHO recommendation on tranexamic acid for the treatment of postpartum hemorrhage: highlights and key messages from the World Health Organization's 2017 global recommendation; 2017. Accessed May 25, 2020, at https://apps.who.int/iris/handle/10665/259379).

13. WOMAN Trial Collaborators. Effect of early tranexamic acid administration on mortality, hysterectomy, and other morbidities in women with postpartum hemorrhage (WOMAN): an international, randomized, double-blind, placebocontrolled trial. Lancet 2017; 389:2105-16.

14. Peitsidis P, Kadir RA. Antifibrinolytic therapy with tranexamic acid in pregnancy and postpartum. Expert Opin Pharmacother 2011; 12(4):503-16.

15. Yang J, Hartmann KE, Savitz DA, Herring $A H$, Dole N, Andrew F. Vaginal bleeding during pregnancy and preterm birth. Am J Epidemiol 2004; 160(2):118-25.

16. Jin J. Babies with low birth weight. JAMA 2015; 313(4):432.

17. Lawn J, Gravett M, Nunes T, Rubens C, Stanton C. The GAPPS Review Group Global report on preterm birth and stillbirth (1 of 7): definitions, description of the burden and opportunities to improve data. BMC Pregnancy Childbirth 2010; 10(Suppl. 1):S1

18. The WHO application of ICD-10 to deaths during the perinatal period: ICD-PM. (Accessed July 9, 2021, at https://apps.who.int/iris/bitstream/ handle/10665/249515/9789241549752-eng.pdf).

19. WHO: Preterm birth 2018. (Accessed 9, July 2021, at https://www.who.int/news-room/factsheets/detail/preterm-birth).

20. American Academy of Pediatrics-Committee on Fetus and Newborn (Replaces Committee Opinion Number 333, May 2006; Reaffirmed 2017). (Accessed May 10, 2020, at https://www.acog.org/Clinical- Guidance-andPublications/Committee-Opinions/Committee-onObstetric-Practice/The-Apgar-Score).

21. Levy JH, Koster A, Quinones QJ, Milling TJ, Key N. Antifibrinolytic Therapy and Perioperative Considerations. Anesthesiology 2018; 128(3): 657-70.

22. Podrasky AE, Javitt MC, Glanc $P H$, Dubinsky TH, Harisinghani MG, et al. ACR appropriateness criteria ${ }^{\circledR}$ second and third trimester bleeding. Ultrasound Q 2013; 29(4):293-301.

23. Bhandari S, Raja EA, Shetty A, Bhattacharya $S$. Maternal and perinatal consequences of 
https:/ / doi.org/ 10.15218/ zjms.2021.017

antepartum hemorrhage of unknown origin. BJOG 2014; 121:44-52.

24. McCormack RA, Doherty DA, Magann RF, Hutchinson M, Newnham JP. Antepartum bleeding of unknown origin in the second half of pregnancy and pregnancy outcomes. BJGO 2008; 115(11):1451-7.

25. Dowswell T, Middleton P, Weeks A. Antenatal day care units versus hospital admission for women with pregnancy complications. Cochrane Database Syst 2009; 7(4):CD001803. 